\title{
SEQUÊNCIAS TEXTUAIS NOS OBJETOS EDUCACIONAIS DIGITAIS
}

\author{
Gregorio Bacelar Lameira \\ Universidade Federal de Pernambuco \\ gregbacelar@gmail.com \\ Marina de Lira Pessoa Mota \\ Universidade Federal de Pernambuco \\ inamota@gmail.com \\ Solange Galvão Coutinho \\ Universidade Federal de Pernambuco \\ solange.coutinho@ufpe.br \\ Eva Rolim Miranda \\ Universidade Federal de Pernambuco \\ evarolim@gmail.com
}

\begin{abstract}
Resumo: Esta pesquisa se dedicou a analisar como se dá a relação de estudantes com objetos educacionais digitais. $O$ interesse do estudo toma por base aspectos de organização das informações nos artefatos digitais e ainda de como é estruturada a sequência textual presente em cada um dos artefatos. Para isso, o artigo se baseia em três momentos: no primeiro são levantadas previamente as definições dos três componentes teóricos da pesquisa, a saber: Design da Informação, sequências textuais e objetos educacionais digitais; no segundo, constituído pela etapa prática, onde se apresenta a utilização dos objetos educacionais digitais por estudantes do ensino fundamental I em uma escola pública na cidade do Recife; e, no terceiro, averiguou-se as relações das conceituações com os dados observados no estudo de caso.
\end{abstract}

Palavras-chave: design da informação, objetos educacionais digitais, sequências textuais.
Abstract: The aim of this research is to analyze the relationship between students and digital learning objects. The interest of the study is based on the organizational aspects of information in digital artefacts, and also how structured textual sequence is presented in each of the artefacts. For this, the article is based on three stages: the first, the definitions of three theoretical components of the research are initially introduced, namely: information design, textual sequences and digital learning objects; the second is a practical step where the digital learning objects are used by elementary schoolchildren in a public school in the city of Recife; the third investigates the relationships of the concepts with the data observed in the case study. 
Palavras-chave: Information design, digital learning objects, structured textual sequences.

\section{INTRODUÇÃO}

Graças aos avanços tecnológicos das últimas décadas, aliado a políticas de acesso à internet e laboratórios de informática nas escolas, já é possível perceber as contribuições ocasionadas com a inserção da linguagem audiovisual enquanto ferramenta auxiliar no processo de ensino-aprendizagem. Recursos educativos digitais já são realidade em uma parcela significativa das escolas brasileiras, fazendo com que os professores adaptem suas metodologias de ensino ao inseri-los em seus planejamentos de aulas. Apesar disso, parece-nos importante destacar que ainda há, por parte de muitos educadores, certa resistência em relação ao uso de tecnologias em suas práticas pedagógicas. $O$ exemplo mais claro está na pouca utilização de livros digitais, ofertados pelo Programa Nacional do Livro Didático (PNLD) onde as escolas optam apenas pela aquisição da versão impressa das obras. Destacamos que geralmente essa resistência é involuntária pelo simples motivo de não terem à disposição uma formação em tecnologias digitais para o docente que propicie a utilização dos materiais com os estudantes. No entanto, observamos que seria relevante se houvesse uma integração entre professores e alunos na utilização desses materiais resultando inclusive em uma realimentação às editoras com sugestões de possíveis melhorias tanto na abordagem dos conteúdos quanto em relação aos artefatos em si.

Nesta pesquisa daremos destaque a alguns recursos que compreendem a terminologia adotada pelo governo federal de objetos educacionais digitais (OEDs). Segundo o PNLD estariam inclusos nessa categorização: vídeos, imagens, áudios, textos, gráficos, tabelas, tutoriais, aplicações, mapas, jogos educacionais, animações, infográficos, páginas web e outros elementos (BRASIL, 2013).

Para o experimento utilizamos três tipos de artefatos do tipo OED: jogo, animação e vídeo explicativo. O objetivo foi contextualizar os tipos de sequências utilizados nesses três objetos educacionais digitais buscando elos com o nível de atenção empregado na atividade pelos alunos. Além disso, buscou-se analisar os porquês da aceitação de um em detrimento de outro levando em consideração aspectos referentes ao Design da Informação.

Partindo dessas explanações, apresentamos algumas questões que sugerimos como reflexão ao longo do artigo, a saber: como se dá a produção e utilização dos recursos digitais em sala de aula? Com quais sequências (narrativas ou descritivas) o estudante se sente mais confortável em aprender? Como as sequências referentes aos objetos analisados podem ser mais bem exploradas?

\section{DEFINIÇÕES}

A seguir apresentamos brevemente alguns conceitos referentes aos três componentes teóricos desse estudo, que auxiliarão, na sequência, na compreensão do estudo prático, são eles: Design da Informação, narrativas sequenciais e objetos educacionais digitais. 


\subsection{Design da Informação}

O processo de mudança das definições acerca do Design da Informação vem ocorrendo desde o início do século XX, quando do projeto do ISOTYPE (International System of Typographic Picture Education) pelo cientista social Otto Neurath (18821945). As práticas projetuais em Design sofreram e vem sofrendo reflexos desse sistema de linguagem pictórica até os dias de hoje. Em seus estudos, um profissional aqui caracterizado como designer - seria o responsável pela transformação da informação, criando um "conteúdo" e não somente trabalhando sobre sua "forma" (LIMA, 2008). Cabe destacar que esse profissional não trabalharia sozinho, mas sim em equipe, de diferentes campos científicos, tal como foi feito na concepção do ISOTYPE. E essa é justamente uma das recorrências encontradas no campo do Design da Informação: a multidisciplinaridade. Como defende Cristina Portugal (2013, p.105):

\footnotetext{
O Design da Informação é uma área relativamente nova e podemos dizer que é uma disciplina emergente e conjuga conhecimentos multidisciplinares que recebe contribuições provenientes de profissionais de diferentes formações e, como qualquer outra especialidade do Design, nela identificase influências de várias áreas do conhecimento. (PORTUGAL, 2013, p.105).
}

Essa ideia é ainda presente como assinalam: Frascara (2011), ao indicar que o design da informação tem sustentação em bases da ergonomia, da linguística, da psicologia, da sociologia, da antropologia, do design gráfico e das ciências da computação - entre outras áreas - visando o entendimento pelo usuário além da utilização de produtos, serviços, instalações e ambientes; Bonsiepe (2011, p. 86), ao afirmar que apesar de não se ter desenvolvido uma teoria coerente da informação, não falta prática por parte do designer de informação "com conhecimentos da psicologia cognitiva, linguística, teoria da percepção, teoria da aprendizagem, semiótica e design visual"; e, Martins \& Couto (2008), que complementam ao identificar distinções entre as metas do Design da Informação e do Design Gráfico, onde na primeira área se dá importância à construção de informações objetivas visando o alcance de resultados precisos. As autoras complementam identificando sujeito e ambiente onde a informação está inserida como essenciais para a construção de sentido das mensagens, entendendo a familiaridade do usuário na interação com a mensagem e o contexto como fundamentais no processo.

Encontramos ainda nas definições de Design da Informação autores que revelam os objetivos deste campo. Destacamos Frascara (2011) que aponta que Design da Informação deve assegurar a efetividade da comunicação e facilitar processos de percepção, leitura, compreensão, memorização e uso da informação apresentada, devendo ser, necessariamente, design centrado no usuário; e Horn (1999, p. 15), ao definir como "a arte e a ciência de preparar informação" para que seja utilizada com eficiência e efetividade, tendo como objetivos primários a elaboração de documentos compreensíveis e de fácil apreensão por seus usuários.

\subsection{Sequências textuais}

Os pressupostos da linguagem, mais especificamente os da linguística textual, nos revelam uma tipologia de sequências que caracterizam o modo de construção do texto. Destacamos aqui uma visão mais ampla do termo "texto", como aquele que aprendemos na semiótica, referindo-se a um objeto, ao mesmo tempo linguístico e 
histórico, que tem em sua estrutura aspectos que garantem que o sentido seja apreendido em sua globalidade, tornando o significado de cada parte dependente do todo (FIORIN, 1995). A seguir, temos as sequências textuais e suas principais características (FIGUEIREDO, 2009):

- Argumentação: meio de orientar o discurso a fim de sustentar determinadas conclusões;

- Descrição: trata-se de uma informação mais pontual/detalhada acerca de algo ou de alguém;

- Exposição: caracteriza-se pela intenção de facilitar a compreensão ao ouvinte/leitor através de informações baseadas em afirmações e logicidade na ordenação de conceitos;

- Injunção: aquela que contém expressões de ordem ou linguagem apelativa/imperativa, com caráter instrucional, circunstâncias de finalidade, etc.;

- Diálogo: refere-se ao texto em formato de diálogo, mesmo que apareça apenas um interlocutor de forma explícita, apresentando turnos de fala e/ou perguntas e respostas;

- Narração: relato de acontecimentos, reais ou fictícios, que abrange ação e personagem(ns).

Dentre as sequências acima caracterizados nos atentaremos mais adiante a duas que foram identificadas nos objetos educacionais digitais durante o experimento: as expositivas e as narrativas.

\subsection{Objetos Educacionais Digitais}

A fundamentação teórica acerca dos objetos educacionais digitais (OED) não obteve ainda precisão e solidificação necessárias para um alcance completo de sua conceituação. Isso ocorre quando pensamos de maneira conjunta no significado das três palavras que compõem a terminologia, mas é razoável analisar cada termo isoladamente. É possível verificar em que campo esses materiais estão inseridos, neste caso na educação, com fins de potencializar o processo de ensino-aprendizagem, assim como averiguar sob qual aspecto - se o digital ou eletrônico -, porém nem sempre com a interação e seu caráter multimídia que se esperam desses recursos (GARCÍA, 2010, p. 100). Já o termo "objetos" pode se referir tanto aos aspectos tangíveis quanto intangíveis de sua composição, visto sua utilização em diferentes áreas do conhecimento. Aqui, tais objetos serão entendidos como recursos implementados em dispositivos eletrônicos, possuindo como característica principal o alto grau de reutilização.

Reforçamos neste estudo a equivalência entre as terminologias "objeto educacional digital" e "objeto de aprendizagem". O primeiro termo foi delimitado nos editais do Programa Nacional do Livro Didático, com a inclusão desses recursos nos hiperlivros a partir do ano de 2013. No entanto outras frentes, também ligadas ao Ministério da Educação, já vinham produzindo os mesmos materiais colocando-os em repositórios online com a nomenclatura de objetos de aprendizagem (OA).

Segundo a Rede Interativa Virtual de Educação (RIVED) esses recursos são considerados como qualquer material eletrônico que provém informações, seja em 
forma de imagem, página html, animação ou simulação envolvendo atividades multimídia e interativas. Atentando-se à funcionalidade dos OA, Lima Filho \& Waechter (2013) indicam que a missão destes objetos é explicar/ilustrar conceitos e processos, com a finalidade de reduzir a complexidade da informação, colaborando na compreensão do conteúdo, algo muito próximo às definições referentes ao Design da Informação, que vimos anteriormente.

\section{METODOLOGIA}

Nesta etapa, selecionamos três OEDs diferentes, mas que abordam o mesmo conteúdo, utilizados por dois grupos de alunos do ensino fundamental I, do 3ㅇaㅇ ano da rede municipal de ensino da cidade do Recife. Em nosso estudo não há a pretensão de avaliar a aprendizagem dos estudantes na utilização dos artefatos, e sim perceber, através das observações e do grupo focal realizados, como é feita a contextualização das sequências presentes nesses objetos e as relações existentes com o cotidiano e vivência das crianças. Aliado a isso apresentamos como se deu a atenção empregada na atividade pelos alunos.

\subsection{Contexto}

O local de realização do experimento foi uma escola municipal no centro da cidade do Recife, com alunos da turma do 3 o ano do Ensino Fundamental I. Os participantes eram nove alunos com idades entre 8 e 12 anos. $^{1}$

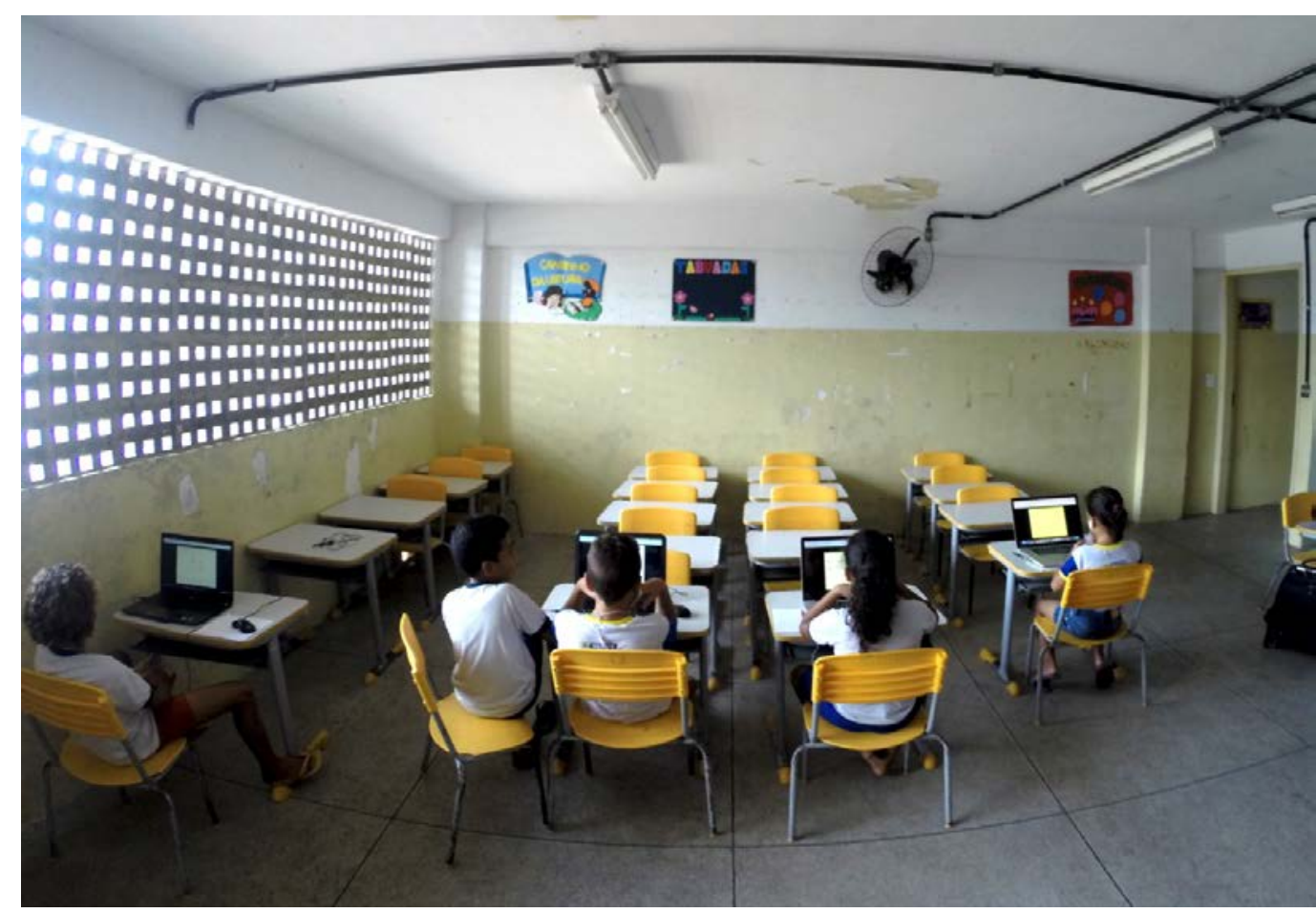

Figura 1 - Espaço do experimento.

Fonte: Imagem dos autores.

\footnotetext{
${ }^{1}$ Há um desnivelamento na turma devido a atrasos na capacidade de aprendizado de alguns alunos.
} 


\subsection{Instrumentos}

Para o experimento foram utilizados quatro notebooks e quatro fones de ouvido (um para cada aluno), com os OED já inseridos nos computadores.

O primeiro foi um jogo de cálculo mental de adição e subtração do Núcleo de Desenvolvimento de Objetos de Aprendizagem Significativa (NOAS), um núcleo de computação aplicada destinado ao desenvolvimento de objetos de aprendizagem; o segundo foi um vídeo explicativo de subtração por reagrupamento da Khan Academy, um portal que oferece exercícios, vídeos de instrução e um painel de aprendizado personalizado, fazendo com que os estudantes aprendam no seu próprio ritmo dentro e fora da sala de aula; e por último, uma animação também sobre adição e subtração com reagrupamento da Editora Moderna, material multimídia aprovado pelo Programa Nacional do Livro Didático (PNLD).

\subsection{Experimento}

Por questões de logística, a atividade foi realizada com um grupo de quatro alunos e outro com cinco alunos. No primeiro momento ocorreu a interação dos alunos com os OED, primeiro começando pelo jogo (5 - $8 \mathrm{~min}$ ), depois o vídeo (5 $\mathrm{min}$ ) e por último a animação ( $6 \mathrm{~min}$ ), conforme mostram as figuras 2,3 e 4 a seguir:

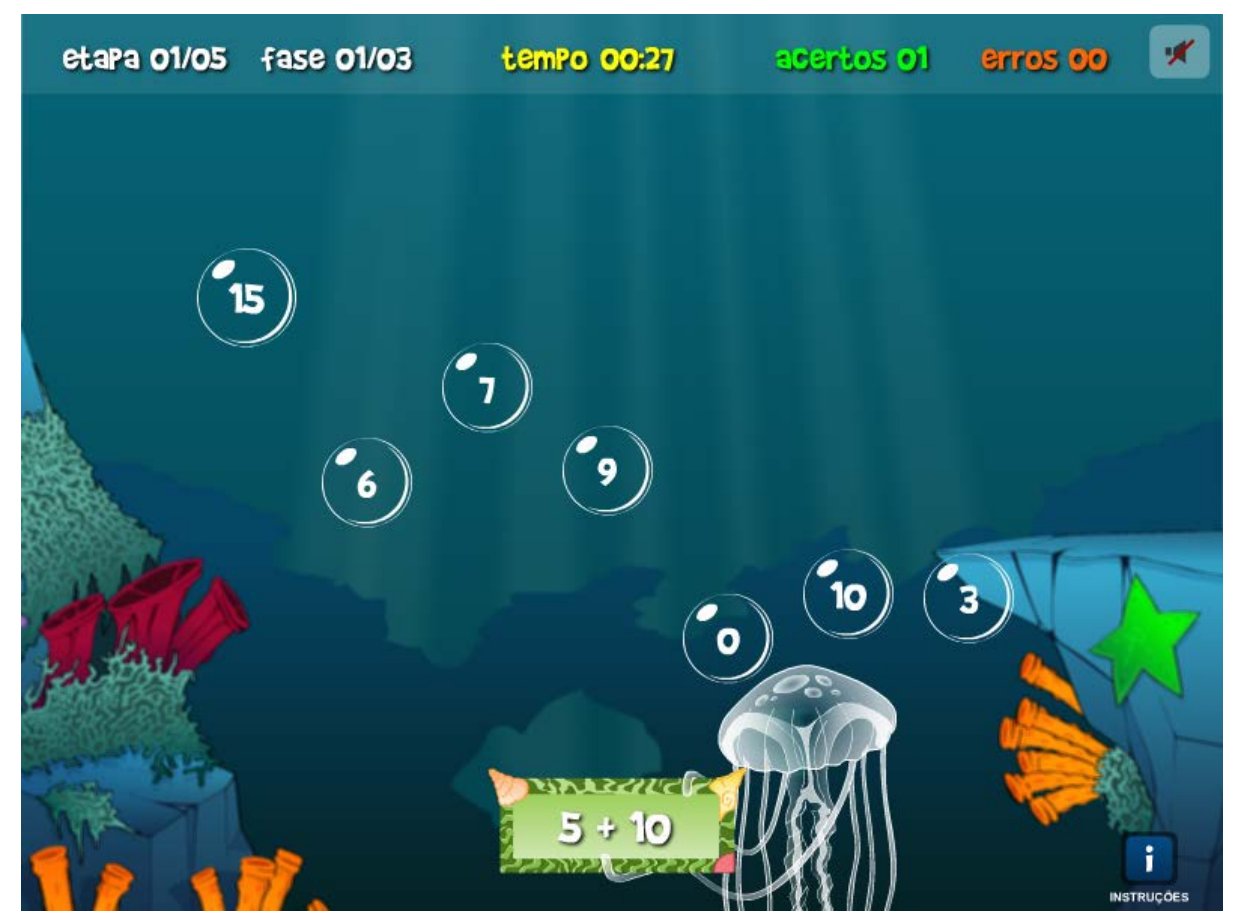

Figura 2 - jogo de cálculo mental de adição e subtração do NOAS.

Fonte: Site do Núcleo de Desenvolvimento de Objetos de Aprendizagem Significativa (NOAS). Disponível em <http://www.noas.com.br>. 


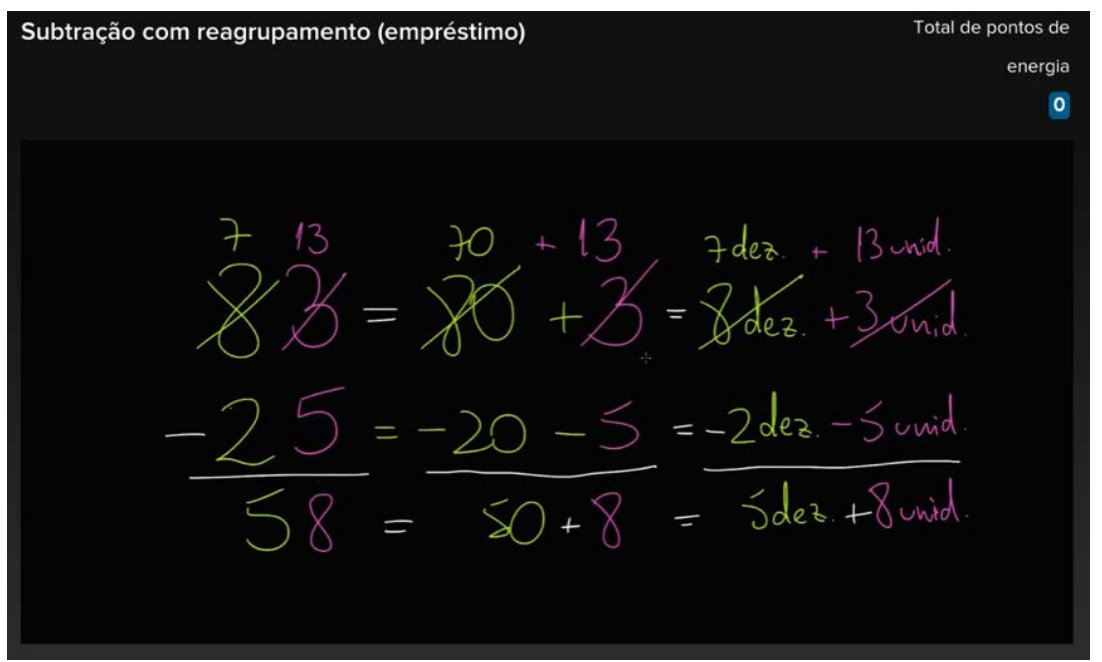

Figura 3 - vídeo explicativo de subtração por reagrupamento da Khan Academy.

Fonte: Site da Khan Academy. Disponível em <https://pt.khanacademy.org>.

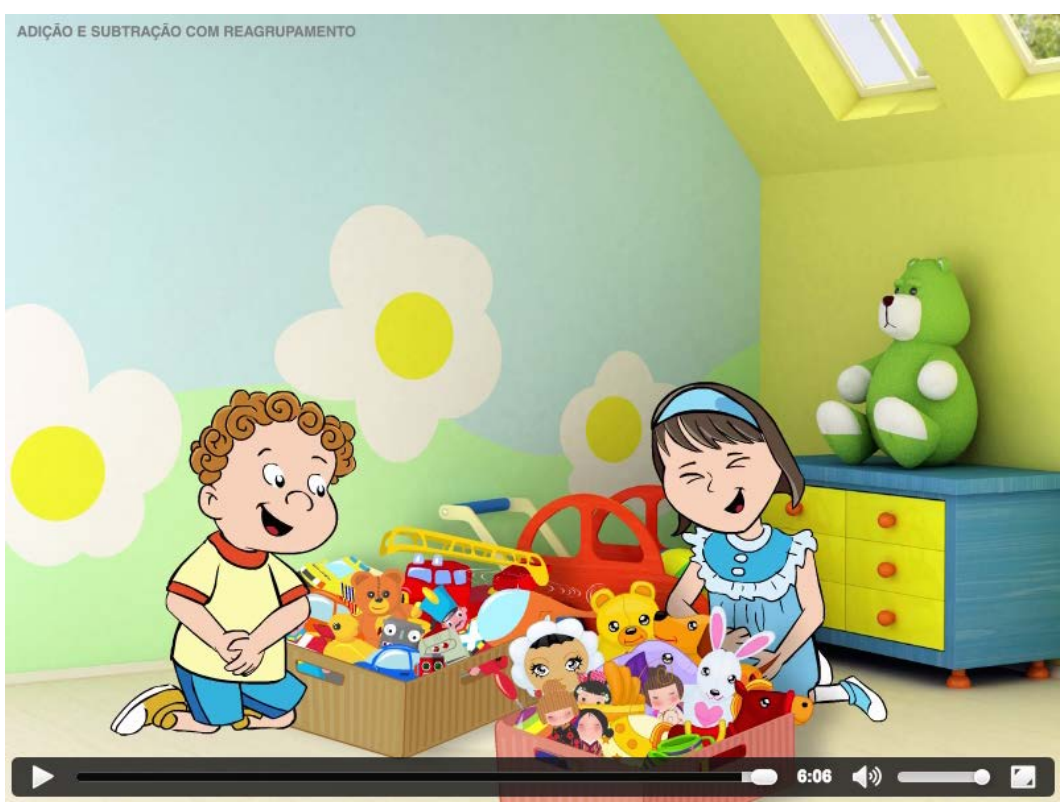

Figura 4 - animação também sobre adição e subtração com reagrupamento da Editora Moderna.

Fonte: Site da Rede Interativa Virtual de Educação (RIVED). Disponível em <http://rived.mec.gov.br>.

No segundo momento, foi realizado um grupo focal com os alunos, com o objetivo de verificar com quais sequências textuais cada um se identificou mais, se eles tinham de fato entendido o conteúdo exposto e se conseguiram associar a atividades realizadas no dia a dia. Algumas perguntas exploradas:

a) Qual foi o material que vocês mais gostaram? Por quê?

b) Qual foi o mais difícil? O mais chato? O mais fácil? O mais legal?

c) Como vocês estudam em casa? Usando que materiais?

d) Como gostaria de estudar?

e) Já viveu alguma situação do dia a dia parecida com alguma dos materiais expostos? 


\section{ANÁLISE E RESULTADOS}

Considerando a classificação e características das sequências textuais propostas por Figueiredo (2009), podemos dizer que os OED possuem as características abaixo:

Quadro 1 - Classificação dos OED conforme suas características sequenciais.

\begin{tabular}{|l|l|l|}
\hline Jogo & Vídeo & Animação \\
\hline Descrição & Diálogo & Diálogo \\
\hline Exposição & Descrição & Descrição \\
\hline Narração & Exposição & Exposição \\
\hline & & Narração \\
\hline
\end{tabular}

Fonte: Elaborado pelos autores, com base na pesquisa realizada.

O jogo de cálculo mental envolvendo adição e subtração com e sem reagrupamento é caracterizado como descritivo por estabelecer em sua estrutura elementos que pontuam detalhadamente apenas esses dois conteúdos, sendo condizentes com o que os alunos estão aprendendo em sala de aula. Os cálculos são precisos, e por isso, das respostas inseridas em um grupo de alternativas, os alunos deverão escolher apenas uma correta. Podem ser ainda considerados expositivos por auxiliarem na compreensão dos assuntos tratados, agindo como um facilitador ao tentar cumprir essa tarefa: apresentam informações que devem ser entendidas como corretas a fim de propiciar a internalização dos conteúdos por parte dos estudantes. Por último pode ser indicado como de narração por colocar o usuário em uma trama de história composta por personagens, ações e cenários. Ao combinar diferentes mídias (imagens, sons, textos, animação e interatividade) torna-se uma narrativa mais participativa, dando ao usuário o papel ativo na história (TEIXEIRA \& GONÇALVES, 2015).

O vídeo sobre subtração por reagrupamento da Khan Academy compreende diálogo, mesmo apresentando apenas um interlocutor. Suas falas indicam perguntas, respostas e explicações direcionadas ao usuário que o assiste. Além disso, pode ser caracterizado, assim como o jogo, como expositivo, ao informar de maneira simples, porém lógica (simulando uma lousa e giz) e de ter como intenção a facilitação do aprendizado dos alunos e; descritivo por representar detalhadamente os conceitos referentes ao conteúdo.

Já animação pode ser caracterizada por quatro das seis sequências apresentadas, são elas: diálogo, descrição, exposição e narração. Há, portanto um enriquecimento do objeto educacional digital planejado para que o aluno não se atenha a somente uma característica específica das sequências, fazendo com que elas dialoguem através de seus vínculos construídos.

Também foi verificado com qual artefato os alunos se sentiram mais confortáveis em estudar, a partir de seus gostos pessoais. $O$ resultado foi o seguinte: 
Quadro 2 - Ordem de preferência dos alunos em relação aos OED.

\begin{tabular}{|l|l|l|l|}
\hline & Jogo & Vídeo & Animação \\
\hline 10 Grupo & 1 aluno & 1 aluno & 2 alunos \\
\hline 2o Grupo & 3 alunos & 1 aluno & 1 aluno \\
\hline
\end{tabular}

Fonte: Elaborado pelos autores, com base na pesquisa realizada.

Apesar de um grupo reduzido de participantes e de uma pequena diferença entre as respostas, podemos inferir que a maioria dos alunos preferiram o jogo e a animação ao vídeo explicativo. Isso pode ser explicado devido ao fato de que, no jogo, o aluno precisa controlar a narrativa ao interagir com o objeto, ou seja, o final da "história" depende do desempenho de cada aluno. Ele também está imerso em um cenário lúdico, o fundo do mar, e é necessário que se clique nas bolhas para responder as questões propostas. Há também recursos sonoros, como uma música de fundo em looping e o som de "água se mexendo".

Já a animação, apesar de não permitir que o aluno interaja controlando de fato, possui aspectos de narração, o que pode facilitar a concentração dos alunos durante a atividade. Além de descrever e expor o conteúdo em si, há uma história por trás para contextualizar os fatos e diálogo entre os personagens, o que gera engajamento do aluno.

Enquanto o vídeo explicativo ficou atrás na preferência dos alunos. Apesar de ter o diálogo do interlocutor com o aluno, ele apenas descreve e expõe o conteúdo de forma objetiva, não tendo nenhuma estrutura narrativa por trás.

Durante o experimento notamos que os alunos que citaram preferir o vídeo explicativo foram os que pareceram mais calmos e focados. Talvez os mais agitados tenham preferido o jogo e a animação justamente por conter uma narrativa, que os mantiveram concentrados na atividade, nas condições propostas durante o grupo focal.

Dentre outras respostas relevantes à pesquisa temos que:

1) o material de estudo mais utilizado para as tarefas escolares são os cadernos com as atividades passadas pela professora. No entanto, alguns alunos utilizam o computador - em casa ou lanhouses - para compreender melhor determinado assunto não assimilado tão bem durante a explanação da professora, utilizando vídeos, animações e jogos para este fim;

2) os alunos consideram os OEDs como importantes em sua aprendizagem. Segundo eles, tais objetos causam um estímulo maior que a oratória da docente em sala de aula, reagindo com uma empolgação ainda maior quando seus personagens clássicos preferidos são os responsáveis pela transmissão de algum conteúdo educativo;

3) suas experiências práticas com matemática ainda são limitadas devido à idade, restringindo-se às tarefas dadas pela professora realizadas em casa e pequenas compras em mercados, nas quais devem conferir o dinheiro dado e o recebido como troco. 


\section{CONSIDERAÇÕES FINAIS}

Parece evidente o fato de que a inserção de objetos educacionais digitais em uma atividade reconhecida como complicada - como é o exercício da matemática -, possibilita maior engajamento e interesse da parte dos alunos. Todos os alunos aceitaram com empolgação participar da atividade, inclusive, vários alunos de outras turmas também perguntaram se não poderiam participar ficando atentos e curiosos acerca da atividade.

O fato de alguns objetos deterem narrativas também contribuiu para um maior engajamento dos alunos, pois a estória com seu enredo, cenários, personagens, etc., chama sua atenção, além de contextualizar o conteúdo exposto.

Além disso, como a preferência pelos artefatos foi de fato variada, percebemos que pode ser um indício de um ponto de reflexão emergente, já mencionado no campo da pedagogia nos últimos anos, que é a personalização da educação. Continuase a tratar os alunos como um grupo homogêneo, impondo um ritmo de aprendizagem coletivo, sem entender as particularidades de cada estudante. Parece importante aproveitar as formas plurais de se transmitir um mesmo conteúdo ao se compreender que cada indivíduo aprende de uma maneira diferente. O caráter multimídia presente nos objetos educacionais digitais nos parece uma boa alternativa para essa individualização do ensino, principalmente quando tais artefatos estão presentes em um material contextualizado, ora em livros digitais didáticos, ora inseridos em uma plataforma adaptativa, onde atividades diferentes são propostas a cada aluno a partir de suas reações e respostas.

Mais do que apresentar respostas, o presente artigo almejou incitar a reflexão acerca da relação dos estudantes com os objetos educacionais digitais, na perspectiva de incitar um debate sobre a da adoção dos OEDs no contexto educacional, o seu possível uso e a sua utilidade como suporte ao processo ensino-aprendizagem, assim como ressaltá-los como dispositivo agregador de novas formas exploratórias de conteúdos necessários à formação de nossos jovens educandos.

\section{REFERÊNCIAS}

BONSIEPE, Gui. Design, cultura e sociedade. São Paulo: Blucher, 2011.

BRASIL, M.F. Edital do PNLD 2015. Portal do FNDE - PNLD 2015, Brasilia, 2013.

Disponivel em: <http://www.fnde.gov.br/arquivos/category/165-

editais?download=8304:edital-pnld-2015-ensino-medio-03-07-2013>, 28/07/2015.

FIGUEIREDO, Irislane R. Sequência narrativa: concepções e limites. In: Congresso Nacional de Linguística e Filologia, 2009, Rio de Janeiro. Cadernos do CNLF, 2009. v. XIII. p. 2684-2696. Disponível em:

<http://www.filologia.org.br/xiiicnIf/XIII_CNLF_04/tomo_3/sequencia_narrativa_conce pcao_e_limites_IRISLANE.pdf> 26/09/2015.

FIORIN, José Luiz. A noção de texto na semiótica. In: Organon. Porto Alegre, v. 9, n. 23, p.163-173, 1995. Disponível em: <http://seer.ufrgs.br/organon/article/view/29370> 26/09/2015.

FRASCARA, Jorge. El diseño de información: una vision de conjunto. In: ¿Qué es el 
diseño de información? Buenos Aires: Editorial Infinito, 2011. p. 11-21. Disponível em: $<$ https://pt.scribd.com/doc/108727498/Diseno-de-informacion-Frascara\#scribd>, 25/04/2015.

GARCÍA, Sergio Álvarez. Uso de contenidos educativos digitales a través de sistemas de gestión del aprendizaje (LMS) y su repercusión en el acto didático comunicativo. 2010. 1008 f. Tese de Doutorado - Universidad Complutense de Madrid, Madrid, 2010. Disponível em: <http://eprints.ucm.es/11631/1/T32372.pdf> Acesso em: 20/09/2015.

HORN, Robert E. Information Design: Emergence of a New Profession. In Jacobsen, Robert. (Ed.), Information Design (online). Cambridge, MA: MIT Press, 1999. Disponível em: <http://web.stanford.edu/ rhorn/a/topic/vl\%26id/artcllnfoDesignChapter.html>, 20/04/2015.

LIMA, Ricardo Cunha. Otto Neurath e o legado do ISOTYPE. InfoDesign - Revista Brasileira de Design da Informação 5(2), 36-49 (2008). Disponível em: <http://infodesign.emnuvens.com.br/infodesign/article/view/54>, 20/04/2015.

LIMA FILHO, Marcos Antonio de ; WAECHTER, Hans da Nóbrega. Desenvolvimento de um objeto de aprendizagem interativo para tablet. In: 60 Congresso Nacional de Ambientes Hipermídia para Aprendizagem. João Pessoa, 2013. Disponível em: $<$ http://66.7.199.78/ andreenr/Anais-CONAHPA-2013/assets/desenvolvimento_ objeto_marcos.pdf $>$, 02/08/2015.

MARTINS, Bianca Maria Rego; COUTO, Rita Maria de Souza. Design da Informação e a construção de sentido no desenvolvimento de materiais educativos. 8 o Congresso Brasileiro de Pesquisa e Desenvolvimento em Design, 2008, São Paulo. Disponível em:<http://www.researchgate.net/publication/273204833_Design_da_Informao_e_a_ construo_de_sentido_no_desenvolvimento_de_materiais_educativos>, 20/04/2015. PORTUGAL, Cristina. Design, Educação e Tecnologia. Rio de Janeiro: Rio Books, 2013. RIVED. Padrões Rived. Disponível em: <http://rived.mec.gov.br/site_objeto_lis.php>, 06/07/2015.

TEIXEIRA, Deglaucy Jorge; GONÇALVES, Berenice Santos. Interatividade e imersão em narrativa digital de ebook interativo infantil, p. 696-709 . In: C. G. Spinillo; L. M. Fadel; V. T. Souto; T. B. P. Silva \& R. J. Camara (Eds). Anais do 70 Congresso Internacional de Design da Informação/Proceedings of the 7th Information Design International Conference | CIDI 2015 [Blucher Design Proceedings, num.2, vol.2]. São Paulo: Blucher, 2015. 